\title{
How fluids infiltrate through fractures and change metamorphic rocks - a case study from northern Spitsbergen
}

\author{
Karol Faehnrich ${ }^{1}$, Karolina Kośmińska ${ }^{1}$, Jarosław Majka ${ }^{1,2}$, Maciej Dwornik ${ }^{1}$ \\ ${ }^{1}$ AGH University of Science and Technology, Faculty of Geology, Geophysics and Environmental Protection; \\ al. A. Mickiewicza 30,30-059 Krakow, Poland; e-mail: karolfaehnrich@wp.pl \\ ${ }^{2}$ Uppsala University, Department of Earth Sciences, Sweden
}

(C) 2016 Authors. This is an open access publication, which can be used, distributed and reproduced in any medium according to the Creative Commons CC-BY 4.0 License requiring that the original work has been properly cited.

Metasomatism is a process leading to changes in the chemical composition of a rock or its portion. It involves introduction or removal of chemical components due to the interaction of the rock with aqueous fluid (Zharikov et al. 2007). Here we present a case study of metasomatic changes in metapelites from northern Spitsbergen. There is a visible metasomatic zonation in the studied samples. The most intense changes are observed close to the contact with fractures, whereas the zones farther away from them are less altered or not affected by fluids at all. Thin sections were prepared from all of the aforementioned zones. The mineral chemistry was obtained using a JEOL SuperProbe 8230 electron microprobe at Faculty of Geology, Geophysics and Environmental Protection, AGH University of Science and Technology.

Mineral assemblage varies from Grt-Bt-Qtz-Pl in zones that were not affected by fluids to GrtChl-Bt-Qtz-Pl in altered portions of the rock. Garnet forms subhedral crystals with abundant quartz inclusions. Its composition is changing from $\mathrm{Alm}_{0.56} \mathrm{Sps}_{0.11} \mathrm{Prp}_{0.05} \mathrm{Grs}_{0.28}$ in the core to $\mathrm{Alm}_{0.64} \mathrm{Sps}_{0.03} \mathrm{Prp}_{0.09} \mathrm{Grs}_{0.24}$ in the rim. It shows bell-shaped Sps profile and opposite Alm trend, indicating one-step progressive garnet growth. Plagioclase composition is characterized by $\mathrm{Ab}_{74.16} \mathrm{An}_{24.39} \mathrm{Or}_{1.44}, \mathrm{~K}$-feldspar also occurs along with Fe-chlorite. Point counting technique was used to estimate volume percentage of minerals.
For each thin section one thousand points were counted. Plagioclase, quartz and biotite are the main phases, building more than $95 \%$ of the rocks. The amount of garnet oscillates around 2\% and chlorite varies from $2.38 \%$ to $0 \%$. Point counting technique was compared with image analysis, which was performed using the Matlab software. The image analysis revealed that the amount of biotite is changing in different zones from $35.42 \%$ to $37.38 \%$, whereas chlorite from $1.54 \%$ to $0 \%$, respectively.

The redistribution of elements between biotite and chlorite was investigated by volume and mass-balance using Gresens (1967) approach. During chloritization of biotite amount of $\mathrm{H}_{2} \mathrm{O}$ in the system must have increased by ca. $8 \%$ in order to form $2.4 \%$ chlorite. Potassium released during this reaction was bonded to secondary K-feldspar, which is apparent on BSE images, and it is closely associated with biotite and chlorite.

This study reveals that metasomatic zones significantly differ in mineralogical composition and fluid-induced alterations are more pervasive closer to the fractures. It has also been concluded that replacement of biotite by chlorite required aqueous fluids, with inflow and outflow of metallic ions and formation of $\mathrm{K}$-feldspar as a product of biotite breakdown reaction. Further investigations will involve X-ray mapping using the XMap Tools software in order to obtain more in depth 
information on volume of minerals and their chemistry. Pressure and temperature conditions of metamorphism will be determined using garnet-biotite geothermometry and thermodynamic modelling. Isocon method will be used to track changes in whole rock chemistry due to interaction with fluid (Grant 1986, 2005).

The study was financed from the statutory research project No 11.11.140.319 and 11.11.140.613, AGH University of Science and Technology.

\section{REFERENCES}

Grant J.A., 1986. The isocon diagram-a simple solution to Grasens equation for metasomatic alteration. Economic Geology, 81, 1976-1982.

Grant J.A., 2005. Isocon analysis: A brief review of the method and applications. Physics and Chemistry of the Earth, 30, 997-1004.

Gresens R.L., 1967. Composition-volume relationship of metasomatism. Chemical Geology, 2, 47-55.

Zharikov V.A, Pertsev N.N., Rusinov V.L., Callegari E. \& Fettes D.J., 2007. Metasomatism and metasomatic rocks. Recommendations by the IUGS subcommission on the systematics of metamorphic rocks, 9 . 